Harry Giles

Prefabricated Construction using

Digitally Integrated Industrial Manufacturing

\footnotetext{
Harry Giles

Professor

University of Michigan

Ann Arbor

USA

hgiles@umich.edu
} 


\title{
Prefabricated Construction using Digitally Integrated Industrial Manufacturing
}

\begin{abstract}
The paper describes research being carried out in relation to prefabricated high density affordable housing under a grant from the Partnership for the Advancement of Technology in Housing (PATH) and the National Science Foundation (NSF) in the USA. The objective is to demonstrate how a new paradigm for the conceptualization and construction of buildings can be conceived of as an entirely factory based process that creates advantages for construction through industrial systems technology transfer. Our approach is intended to transform design methodology through demonstrating how alternative construction concepts, using entirely pre-manufactured volumetric units, can be adopted. This involves digital modeling that facilitates parametric variations for creating customized prefabricated products from design conceptualization through to final product delivery. The paper discusses key areas under investigation in relation to a manufacturing paradigm used in the automotive industry that integrates virtual prototyping and industrial manufacturing systems. Our research explores a type of monocoque volumetric unit prefabricated in steel, which will be pre-finished as part of a modular factory-built approach using industrialized methodologies that will facilitate customized manufacture of a high quality energy efficient product for affordable housing.
\end{abstract}

The paper addresses the automotive industry methods of manufacture that have served increased automobile performance and economics through mass production for over a century. In stark contrast, the building industry and in particular the housing industry is still a century behind. It is suggested that a move away from tradition will require an industry wide initiative, just like Henry Ford led the way with mass production. By embracing the increasing sophistication and capability that digital technology offers, it is shown how digital tools are implemented towards mass customization in house design using virtual modeling in the context of a prefabricated manufacturing approach. This includes industrialized modular sub-assembly design, where the information on parts, assemblies and modules can be transferred to digital and robotic technology, as seen in the automotive industry, as well as achieving enhanced production efficiency through a 'supply chain' process, which is condensed. The paper discusses how these models for manufacture can be transferred into the housing market in order to revolutionize the cost and quality base of construction. Our research objective is to disseminate knowledge on this process, and showing how through integrated transfer of automotive technologies we can implement an industrialized fabrication process for mass housing, not previously known in the building industry.

49 - ARCC Journal / Volume 5 Issue 2 - 49 
A key focus of our evolving research and development is to enable mass customization or delayed differentiation through virtual prototyping that becomes the central organizing element for design. This transfers through to the supply and implementation of housing using industrialized production line manufacture of a product. The expected outcomes of this research and the conclusions drawn in this paper will demonstrate the means by which to achieve more accessibility to affordable housing for society at large and how through successful design integration and an industrial basis for manufacture will provide an adaptable set of affordable housing typologies for diverse demographic needs.

\section{INTRODUCTION}

This paper shows how high quality affordable housing is being researched through an integrated strategy that combines socio-economic considerations with technological imperatives. Currently affordable housing availability and quality suffers due to obstacles that fundamentally lie within current design culture and construction that shies away from past stigmas. Current practice perpetuates a traditional style and construction ethic that continues to encourage urban sprawl, undermines progress, and blocks opportunities for affordable housing. Integrated socioeconomic approaches to these issues together with technological innovations can make high quality affordable housing more accessible. These issues are being addressed in the author's current research in technological innovations in the development of industrially designed modular concepts for low-energy, multi-story, prefabricated, compact affordable housing. This work is being carried out under a grant funded by the Partnership for Advancement of Technology in Housing (PATH) and the National Science Foundation (NSF) in the USA, as part of a national initiative for promoting higher quality and value in housing through the implementation of effective technologies.

A key issue for the housing industry is the fragmentation among various industry stakeholders, with its communication impediments and slow adoption of new housing technologies [1]. Our research has been focusing on developing a new paradigm for housing design and manufacture that includes spatial arrangements and volumetric configurations, through to fabrication, delivery to site, and erection. This research proposes a 'revolution' in housing construction that is based on manufacturing being entirely factory based rather than site based. Although there are a number of companies that produce 'modular prefabricated' homes, throughout the world, including Toyota and IKEA, they have yet to implement effective manufacturing methods used in the car industry towards more affordable high density multifamily housing. Toyota appears to only pride itself in providing 'comfort and luxury' in houses in Japan. [2] , a typical example of their product is shown in Figure 1.

The steel-framed Toyota prefabs leave the assembly factory $85 \%$ complete; in half a day, the modules get stacked into place with a crane. The company offers various sizes and designs, with an average family home comprising 12 modules and costing about \$225,000 [2] 


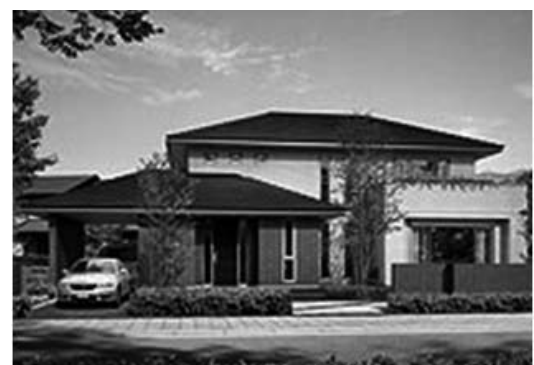

Figure 1

Toyota prefabricated housing example [2]

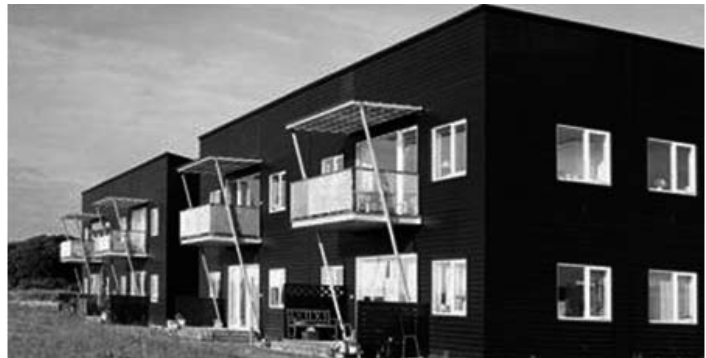

Figure 2

IKEA 'Boklok' prefabricated housing example [3]

IKEA 'BoKlok' homes are timber-framed buildings, almost entirely prefabricated. They are usually brought to the site on the back of trucks as pre-assembled units, with the interiors already fitted out. Each apartment is made up of two of these units, which are moved into position by crane. The typical BoKlok arrangement is an L-shaped, two-storey block with three apartments on each floor. [3] Again, these houses are targeted at the single family market and are limited in their application to low rise construction because of the timber structural framing.

In the USA prefabricated homes are generally single family and little more that assembling parts of a building under a factory roof (taking advantage only of the environmental conditions), but still practicing traditional construction methods. The industry needs to transform radically if it is to come close to providing the kinds of statistics that the auto industry is able to show in terms of cost efficiency and final quality of product. In addition, these developments in prefabricated home design and delivery do not address the most pressing need for good quality, affordable high density housing.

\section{A PRODUCT DESIGN APPROACH}

We are therefore developing a methodology for the application of technology to house manufacturing methods for high density, multi family affordable applications that readily integrate technologies related to social sustainability and low-energy consumption. A whole-house prefabrication concept integrates building services into the enclosure, similar to the design of automobiles. The enclosure is conceived of as an innovative hybrid monocoque (or unibody) metal skin enclosure that is stacked vertically to form multi-story, prefabricated volumetric housing modules. It minimizes the number of parts to be made for the structure and maximizes on its inherent stiffness as a uni-body both for transportation and final performance. The material components, enclosure, and environmental systems are integrated with passive energy systems to create a prototype for modern living. Society readily embraces the modern comforts and technologies of other industries such as automotive, aerospace and electronics, yet when it comes to homes, we continue to live on a contradictory cocktail that mixes synthetic and romantic notions of habitation. These issues are key factors that create barriers against effective

51 - ARCC Journal / Volume 5 Issue 2 - 51 


\section{Production-Bullding Enclosures- Energy and Whole House Design Research}

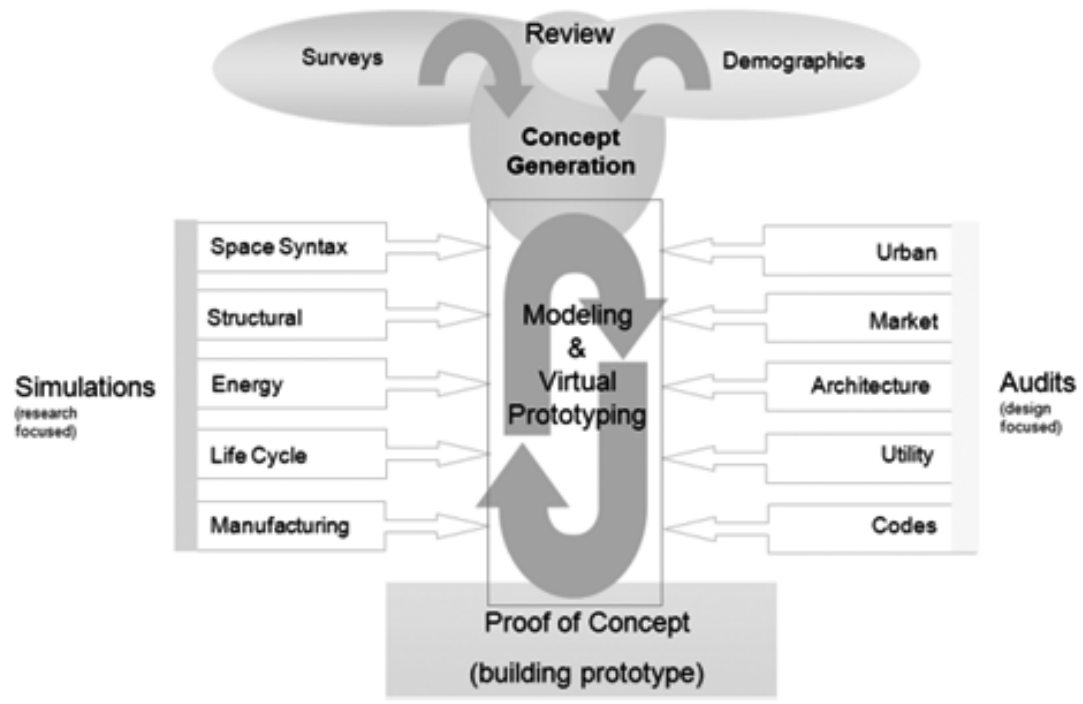

\section{Figure 3}

Product Design Development Model

improvements in the housing industry. New technologies continue to be 'attachments' that tinker around the edges of what could become an effective solution with universal acceptance for housing. Our model for design and delivery follows a Product Design Development Model that transforms traditional approaches to construction into a more product based industrialized design approach as shown in Figure 3.

In addressing the many and complex issues surrounding the integration of design with manufacturing, our research approach shown in Figure 3, includes the iterative process of simulation and audits towards a final proof of concept which include:

- Case Studies and Survey

- Demographics and Space Syntax

- Building Integration

- Prototyping - Virtual and Physical

- Structural Analysis

- Energy Analysis

- Life Cycle Analysis

- Manufacturing Analysis 
It is beyond the scope of this paper to deal with each of the above topics in turn, but rather, the key parameters are discussed and examples are shown of the kinds of approaches and outcomes that are emerging from our research.

Unlike the consumer market that thrives on the latest in fashion and gadgetry, the housing industry is generally still steeped in the tradition of making homes that pander to some 'romantic' notion of what constitutes the 'appearance' of an ideal home. We see this being manifest even in the Toyota homes example described previously. This unrealistic 'dream' continues to be fed by home builders that continue to advertise the 'dream home' which is both inefficient and unsustainable. Even Toyota homes are not experiencing success in output, since they are trying to build 'traditional' and customized designs to factory standards and finding it hard to remain economic.

\section{INDUSTRIALIZED PREFABRICATION}

What are the barriers for prefabrication? Unfortunately modular prefabrication in housing has always been synonymous with low cost, low quality, short term housing solutions, resulting in early deterioration of the building fabric and entire neighborhoods. The only real advances in home technologies have occurred at the high end of the market, where only wealthy home owners can afford to squander earnings in new niche technological applications and gadgets in support of a contemporary image and lifestyle, and at the same time securing prime land space available to only the financial elite. None of this is accessible to most of the public at large, let alone low income earners. Unfortunately these are the kind of products and projects that enjoy mass press coverage and continue to pander to architectural aesthetical aspirations. It is left to lowest common denominator and unimaginative home builders to propagate urban sprawl, the majority of housing stock on the market today. Residential homes represent some $70 \%$ of our built environment, and only a fraction of these are influenced by graduating and professional architects who might positively influence this domain. Clearly education on the benefits of a new genre of modern prefabricated housing concepts will be required and take some time to promote. In other industries revolutions have happened historically, such as the Henry Ford revolution - by designing an industrialized product that was more accessible to the masses, with a level of quality that sustained the value of the product and resulted in improved life style changes. We believe that this process can only be effectively accepted by the public at large by implementing model projects that clearly demonstrate the benefits of high density affordable housing advantages. Fortunately, there are some fine examples of this in the UK, constructed since about 1999, with projects such as Murry Grove constructed on an urban regeneration site over 5 floors with 50 apartments [4], including others like Raines Court[7], that demonstrate what is possible both architecturally and urbanistically using prefabricated steel framed modules. An example of this is shown in Figure 4.

We are taking a unique approach. Our basic principles for design follow those similar to industrialized car design, where the essentials of the functions and locations of the chassis, body, engine, wheels, windscreen, drive train, lighting, seats and doors are essentially the same. Where

53 - ARCC Journal / Volume 5 Issue 2 - 53 


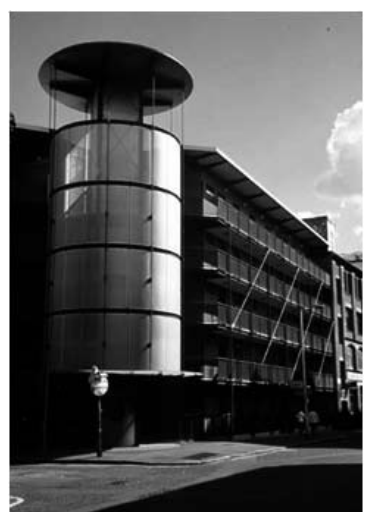

\section{Figure 4}

Murray Grove project UK

- prefabricated steel modular high density affordable housing [4]

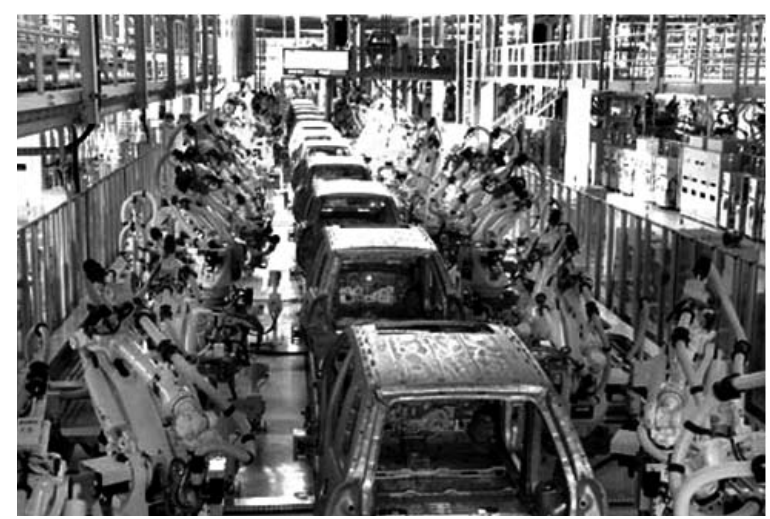

Figure 5

Auto production line using automated robotics at the Hyundai car company. Source http://www.hyundai-motor.com/

the differentiation comes, is in styling. So design and manufacturing optimization takes place in engineering the main functional components to exacting tolerances with minimal waste, and many of the components are reused or reconfigured for different models. Most of the variants also come in the styling and some in the performance. Therefore we have developed a robust monocoque 'chassis' and 'body' combined, around which variants can take place. This allows our concept to be standardized and overlaid with a customized skin and function. The approach allows both variations (customization) during the design concept phase and later on, to be altered without impairing the building product. Taking a 'whole lifestyle' approach, we have configured a range of dwelling possibilities that cater for various demographics both at the inception stage, with potential for alteration as homeowner demographics change. Some examples of how design flexibility integration can alter with demographic changes are discussed and shown later in the paper.

\section{TRANSFER TECHNOLOGY MODEL}

The car industry started by using traditional materials used in transportation at the time (mostly wood based) but very rapidly progressed to a new paradigm for using new materials and the methods of manufacture (steel) that best optimized on the car design performance, economics through manufacturing opportunities, and eventual disposal and recycling. The building industry and in particular the housing industry is still a century behind. A move away from tradition requires an industry wide initiative, just like Henry Ford led the way with mass production. With the increasing sophistication and capability that digital technology offers, we are now able to produce mass customized products, or as more appropriately stated in the manufacturing industry - delayed differentiation. This requires the production line to be specifically designed and 
installed to be both reconfigurable and accommodate design variants. Automated digitally driven robotics facilitates high volume output for minimal cost in automobile manufacture as shown in Figure 5. The production line is intense and requires significant capital investment based on projected and dependable production volume output. One of the key issues for industrialized modular prefabricated housing is the size of the market, to ensure consistent volumes of production to make the capital investment worthwhile in the marketplace. This has been an ongoing source of concern for fledgling fabricators attempting to enter the housing prefabrication industry. This situation will most likely continue for some time to come until the public at large and hence the marketplace for housing is seen as a type of 'consumer product' that is driven on the same basis as other industrially designed products such as automobiles. The building industry still has a long way to go to get close to industrialized manufacture. For example, at one end of the extreme, the car manufacturer BMW with 70,000 employees in 23 locations claims that they can theoretically produce $10^{\wedge} 17$ unique variations of a BMW 7 Series alone - far in excess of the possible production volume and the earth's population! Some other relevant if not staggering statistics about BMW car manufacture [5] are:

- High flexibility for customers - requests for chassis changes (including motor, color, and equipment) can be handled up to one week before assembly without affecting the agreed delivery date.

- Typically, up to 120,000 BMW change requests are realized per month.

- $\quad$ A typical BMW consists of 20,000 parts.

- Manufacturing precision is measured to thousandths of a millimeter.

All this for a unit price of less than $\$ 50,000$.

One might speculate what it would cost to provide a simple house to the level of accuracy, customization and complexity of a typical automobile. The future does not bode well, considering that a simple affordable 2 bedroom home costs in excess of $\$ 100,000$. However, to speculate even further, if housing construction had at least a small proportional set of comparative industrially manufactured features, it ought not to be too difficult to achieve similar choices, quality and output, still at a competitive price. So what are the barriers that prevent this from happening? This paper attempts to address some of the key issues being researched by the author and demonstrates how this is translating to a transformative approach towards the construction of high density housing in particular.

Kieran Timberlake (4) in their book titled 'Refabricating Architecture" observed how the car industry progressed from an assembly line that deployed one-by-one assembly of unit parts during the time of Henry Ford, towards modern modular assembly where parts and modules are managed automatically using the latest robotic technology. Modular production is best suited in an industry that thrives from a 'supply chain' process which is condensed, so that the best expertise is incorporated with as few parts as possible, which arrive at the point of final assembly in pre-contained modular units. Our approach towards designing a set of modular units, mass customized to the desire of the end user, is consistent with this approach in the automotive industry. We are convinced that by transferring these models for manufacture into

55 - ARCC Journal / Volume 5 Issue 2 - 55 
the housing market, we can revolutionize the cost and quality base of our housing market. However, this will require a quantum shift in the conceptualization and appreciation of what a house represents in a modern world and begin to move away from traditional styles and methods of construction.

\section{RESEARCH CONTEXT}

This research is nearing completions of a three-year project. During the initial phase, our goals were to explore the possibilities of high-density mid-rise housing development using standardized modular prefabricated construction, influenced by the dynamically varying social imperatives that we see in a modern world. As part of this process, we conducted various research-based studios, with diverse faculty who are also part of the research team, to explore the issues listed Product Design Development Model in Figure 3. An initial study was carried out in the form of a design project, based on different sites of varying size, urban context and solar orientation. Based on the success of these initial studios, we developed several prototypical designs based on the guiding principles discussed in more detail in a previous paper [6].

A number of housing typologies were developed as models for technical exploration. The apartment layouts shown in Figure 6, were conceived of as an integrated solution that intersects with manufacturing, structural, environmental, spatial, urban and architectural goals and serve as a template from which parametric variations may be developed for other applications. The aim here was not to develop a fixed model that attempts to solve every aspect of design, but to construct well defined building blocks that become a template for stacking and reconfiguration, that links initial manufacture with final building layouts.

Our concept integrates technology with socio-cultural issues that encourages the diffusion flow. Our target areas for affordable housing are typologies related to multi-story developments that are a combination of low to mid-rise in height, or 3 story walkups to 7 story elevator blocks. In figure $7 \mathrm{a}$, a prototype design is shown, which successfully incorporates all the relevant social and environmental features recommended by the author in a previous paper [6]. Figures $7 \mathrm{~b}$ and $7 \mathrm{c}$, show the apartment distributions based on the typologies referred to in Figure 6, with a demographic mix that caters for the needs of the local area and urban context.

\section{TECHNOLOGICAL CONTEXT}

Our research recognizes the housing industry's inefficiencies and fragmentation caused by the slow adoption of new housing technologies and we are promoting a paradigm shift for construction that uses industrialized manufacturing models and technology transfer in the design and procurement process, through to final climatic and environmental performance. The overarching objective of this research is to create a new way of conceptualizing technologically innovative housing design that integrates environmental, economic and social sustainability. This was conceived through a focus that:

a- Creates advantages for construction using factory-based manufacturing methods

b- Innovates construction concepts using entirely pre-manufactured volumetric units; and

c- Integrates low-energy/whole-house design and sustainable technologies.

56 - ARCC Journal / Volume 5 Issue 2 - 56 


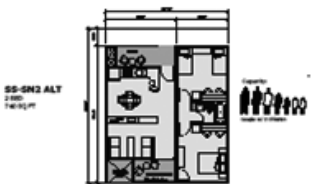
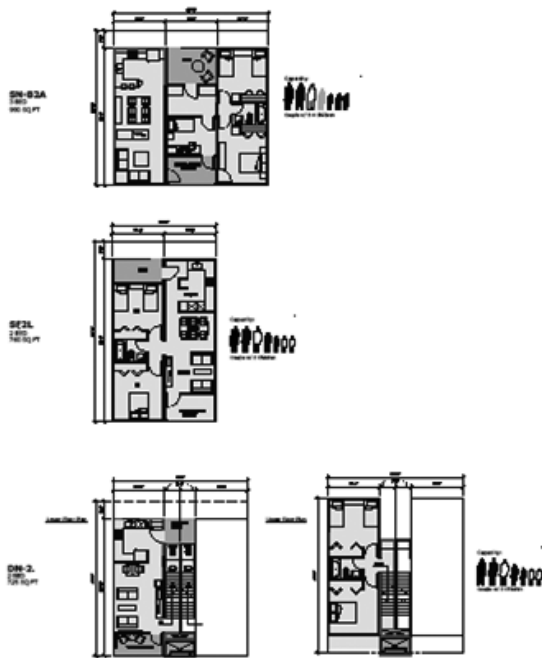

Figure 6

Representative apartment layouts used in project modeling and technology integration

\section{Figure 7A}

Model prototype project

\section{Figure 7B}

Demographic distribution in the project

\section{Figure 7C}

Apartment unit distribution
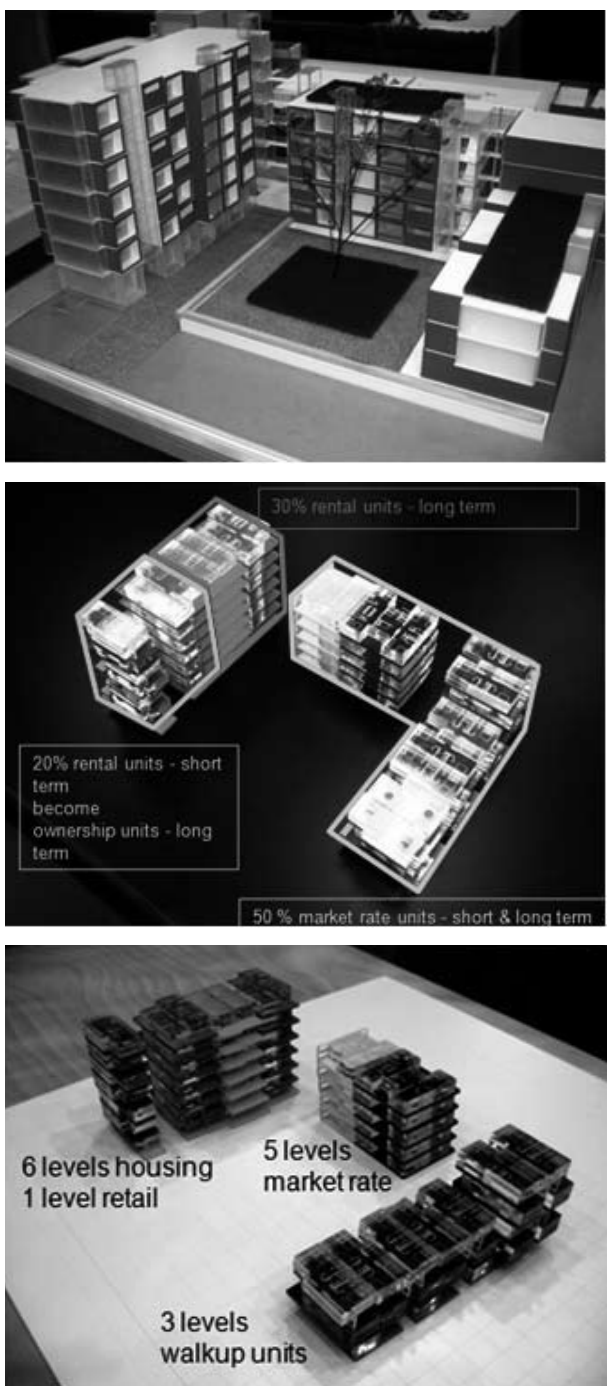

We are attempting to shift the existing paradigm for housing construction, away from conventional layered methods that represent the majority of home building construction techniques seen on the market today. The applications for technologically innovative modular construction are not new, however their application in a new paradigm for housing is new and it is in this area that we are focusing our research and development.

With the increasing sophistication and capability that digital technology offers, we have evolved concepts that both allow increased efficiencies through an industrially produced product and allows for mass customization in house design, using a prefabricated approach based on vir-

57 - ARCC Journal / Volume 5 Issue 2 - 57 
tual digital prototyping to test the process from concept to production line realization. Modular production and "supply chain" process are incorporated into a virtual building model that is used for testing variations, systems integration and manufacture within the Product Design Development Model described previously - similar to the automotive industry manufacturing system. Our approach toward designing a set of modular units, mass customized to the desire of the end user, is consistent with this approach in the automotive industry. We are convinced that by transferring these models for manufacture into the housing market, we can revolutionize the cost and quality base of our housing market. Existing models of so called "pre-manufactured homes" are simply traditional construction methods built under a roof adopting traditional stylistic modeling to entice the single-family home buyer. There is little that is industrialized about the process and even less which is innovative, resulting in a flattened set of "standardized" designs that eventually give the appearance of an on-site built "dream" home, but little else to offer than lower initial cost and consequent lower quality.

This paper will now address a few of the specific areas that relate to this focus in our research:

\subsection{Building Integration}

As part of an entire package for prefabricated modular housing, we have also addressed the role of energy consumption and generation in the context of an integrated design approach. This is achieved through the integration of passive and fresh air systems that provide additional benefits in reducing costs.

The apartment typologies shown in Figure 6 and Figure 7 incorporate a systems approach that integrates services, structure, manufacture, whole building performance and assembly. Each unit type is associated with a particular demographic application, whereas some units are able to serve multi-demographic categories. Therefore the system is able to be implemented at a global building scale that balances regional demographic social with residential needs. The system is also able to be reconfigured within the particular unit to allow varying time related demographic changes. Our research has so far identified the following key components that contribute towards an integrated strategy and have become the key features in the project design concept:

- fresh air distribution systems integration as part of the structural system

- creation of groups of 'parts' to facilitate sub assembly manufacture

- ability to achieve tight tolerances between steel components and units

- exploit non combustible nature of steel compared to wood

- exploit the high strength and stiffness to weight ratio in steel to economically achieve midrise construction heights

- utilize wall and floor decking as an inherently stiff monocoque system to resist lateral loads

- integrate a concrete slab for better acoustic, fire and environmental performance between units

- use sub-assemblies to allow customized design of modules and facilitate future flexibility.

58 - ARCC Journal / Volume 5 Issue 2 - 58 


\section{Figure 8}

Modular building systems integration

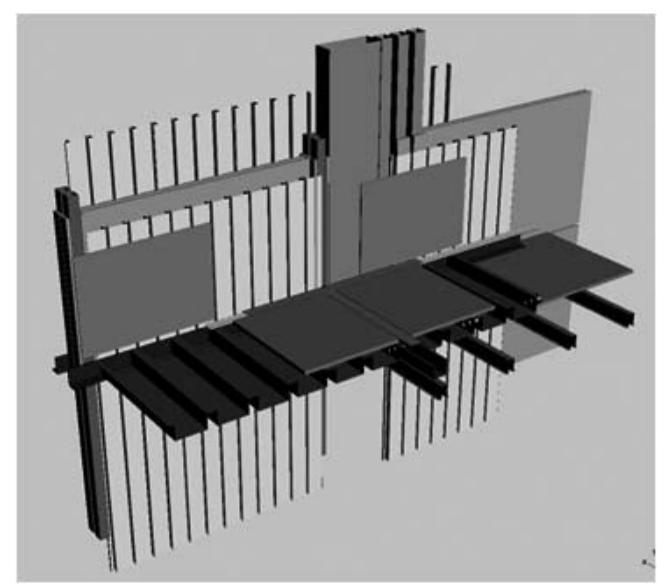

A cutaway detail of integrated structural and enclosure components that are being incorporated in a virtual prototype of the building is shown in Figure 8, which is discussed further in the next section. The initial apartment layout logic system separates living modules from bedroom modules and integrates entrance niches and balcony spaces at the ends of each module. When combined with the access walkway balcony and in some cases internal stairways, these form the essential building blocks from which all apartment unit configurations are developed. Underlying the layout logic is the structural infrastructure that has been highly standardized, but at the same time configured on the basis of systems integration.

This layout logic continues to evolve and improve as the units are layered with various performance criteria and materials. This structural module with its ability for adaptation of components is becoming the underlying DNA that both organize the interrelationships between modules at the bigger scale and materials and fittings at a smaller scale. The structure is configured to fulfill not only a stability function but also an organizing framework within which services are distributed, openings are created and materials are attached.

Figure 9 demonstrates how a set of simple standardized modules can create a variety of apartment unit typologies, all based on an identical structural frame configuration.

The base structural frame also becomes the physical and organizing template for commencing manufacture. This is a significant conceptual leap in the integrated system and also a departure from conventional framing systems used in both traditional construction and as currently practiced in single family modular housing. The field for multifamily housing is still wide open and the modular concept developed goes much further in systems integration, even when compared to similar technologies already used in other countries such as the UK.

\subsection{Virtual Prototyping}

In order to better understand the physical interactions of some of the modular concepts being developed, virtual prototypes of components were developed as they might be conceived of for manufacture. This included modeling of structural systems to build a complete virtual building

59 - ARCC Journal / Volume 5 Issue 2 - 59 
prototype in 3 dimensions for future manufacturing studies and implementation of production prototypes. A cutaway assembly is shown in Figure 10 that shows the development of integrated details for an entire living unit.

These graphics formed the basis of developing 3D parts and sub-assembly modeling for the building virtual prototype, by setting up modeling strategies as shown in Figure 11.

Systems coordination of parts and sub-assemblies are then hierarchally built up into units from modular building blocks. By using various layering strategies in CAD we have set up a system whereby selective building elements can be observed depending on the particular source of interest. For example, the entire steel structural system can be uniquely isolated, printed and bills of materials created using this process. In addition the virtual model is made up of individual 'parts' and 'sub assemblies' that can also be tracked in the management system, both during design development and for final production planning and processing. The design process pre-empts the manufacturing process through virtual prototyping operating as a building information model (BIM).

Our layering naming strategy broadly matches the "MasterFormat" 2004 [8] edition so that the naming systems will be easily recognized by builders and other professionals alike. This strategy is translated into a 3 dimensional virtual prototype that is continuously being developed using 3D solid modeling CAD software. The virtual model is more consistent with the currently established CAD norms in the industrial sector, to further support rapid changes for customization and reconfiguration of production lines. Versions for manufacture are being developed in collaboration with manufacturing partners in order to compare the home manufacturing process with established industrialized manufacturing.

Consistent with the modular assembly approach, we have developed building systems that are based on reconfigurable sub assemblies that will facilitate mass customization, hence breaking away from traditional building approaches. A sub-assembly should be removable as an assembly, and as such this has implications for the methods by which buildings are constructed. This is precisely what our modular concept is developing down to the smaller 'part' or 'component' level of detail - ie. Entire 'plug-in' sub-assemblies are designed to fit into hierarchical frameworks such as large openings housing door or window openings which are each in turn designed to fit a sub-assembly of door and frame or window and frame system. The entire wall subassembly of smaller component parts is then lifted into position to fit into the larger hierarchical structural framework as can be seen in figure 12 which shows a basic virtual 3D prototyping strategy that has evolved into a more complex configuration of sub-assemblies and parts as shown in Figure 13.

Virtual prototyping was expanded from the base module to the larger building unit assemblies and Figure 14a and 14b shows the various volumetric modules combined to create a variety of apartment units both horizontally and vertically, when fully assembled on site to form the entire building complex. Figure 14a represents a color coded separation of living units whereas Figure $14 \mathrm{~b}$, shows the actual completed assembly, showing how the units are indistinguishable exter-

60 - ARCC Journal / Volume 5 Issue 2 - 60 


\section{Figure 9}

A standardized kit of module assemblies provide various living unit configurations

\section{Figure 10}

Virtual prototype cut-away of complete living unit assembly showing key elements.

\section{Figure 11}

Virtual prototype modeling strategies
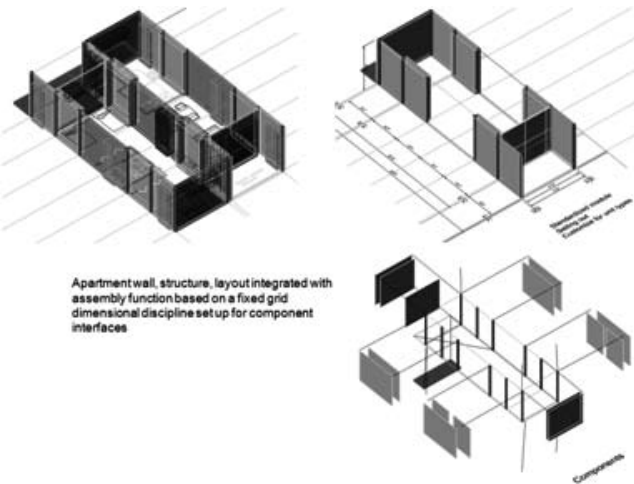

Figure 12

Virtual prototype component interface integration strategy diagram
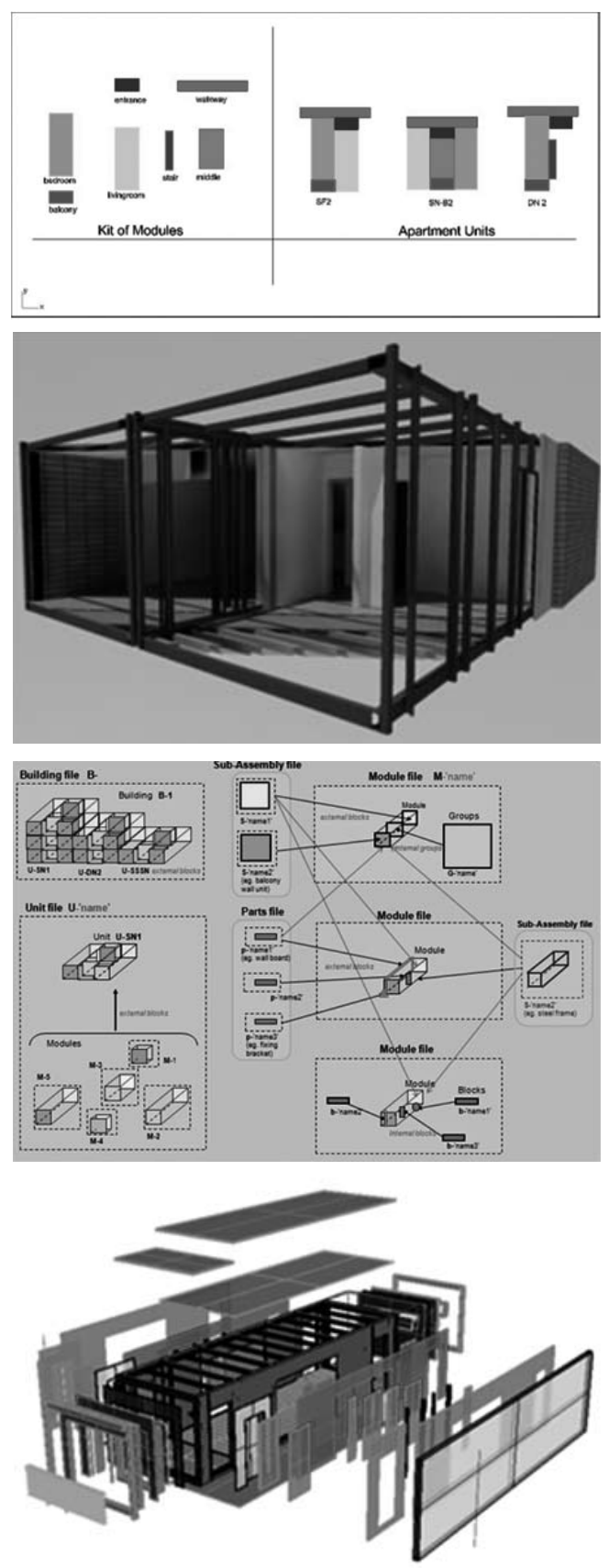

Figure 13

Exploded view of basic module into parts and sub-assemblies

61 - ARCC Journal / Volume 5 Issue 2 - 61 
nally and form a coherent building mass, yet at the same time possessing the rigorous underlying discipline based on the prefabricated module configuration.

The virtual prototype assembly has also been successfully used to model a manufacturing process that is planned for a moving production line. We used this method to disassemble typical modules to their constituent parts and then to reassemble these parts as a series of sub-assemblies to study alternative possibilities for manufacture. One version of a potential assembly process is shown in Figure 15.

An outcome that is emerging from our systematized modular approach is that components and parts can be scheduled uniquely for manufacture, since the graphic building blocks used to make the virtual prototype will become the final item for manufacture. Since each part is uniquely modeled, referenced and dimensioned in the virtual model, they are also the final part that will be manufactured. Figure 16 below demonstrates the kind of hierarchical relationships between part, sub assemblies and module that underlie the expansion of the modular system into ever increasing complexity and variety.

This does not appear to be a difficult task and we expect that as these schedules are generated they will in turn begin to inform the production line infrastructure. As can be seen in Figure 11 , small scale modeling grows from producing parts through sub assemblies to modules, which in turn become units and buildings. That is, the entire building assembly process is traced back to each individual part in the virtual model, so that the production method leads the design development. This might be an anathema to most of the architectural industry that considers design to lead construction. It is this kind of inversion of thinking that will need to take place, in order to fully implement a successful new paradigm for construction.

\subsection{Industrialized Manufacturing}

A key objective of our evolving prototype development is to enable mass customization or delayed differentiation, all of which is founded in the virtual prototype that becomes the central organizing element of the entire design, supply and implementation of the home as an industrial product. As has been demonstrated in car and aircraft design, monocoque structural systems are more efficient in terms of strength-to-weight ratio and possess very high stiffness characteristics.

This is crucial for a volumetric unit that is proposed to be pre-finished, integrally with the modular factory-built approach, to ensure that the final finishes within do not suffer during transportation and installation.

Methodologies for manufacturing analysis that will allow for mass customization have been developed and are being combined with the virtual prototype described previously. 'We have established relevant factors for analysis as it applies to modular prefabricated high density housing. The manufacturing of prefab houses is related to a variety of manufacturing issues such as component fabrication, assembly process design, assembly system configurations, module design, modular component design and supply chain structure. The use of outsourced subassemblies or components strongly affects housing-module assembly sequences and supply chain structure. The total cost includes materials, assembly, inventory holding, labor and trans-

62 - ARCC Journal / Volume 5 Issue 2 - 62 


\section{Figure 14A}

Color coded assembly of living units

\section{Figure 14B}

Coherent assembly of living units showing unified composition of facades.
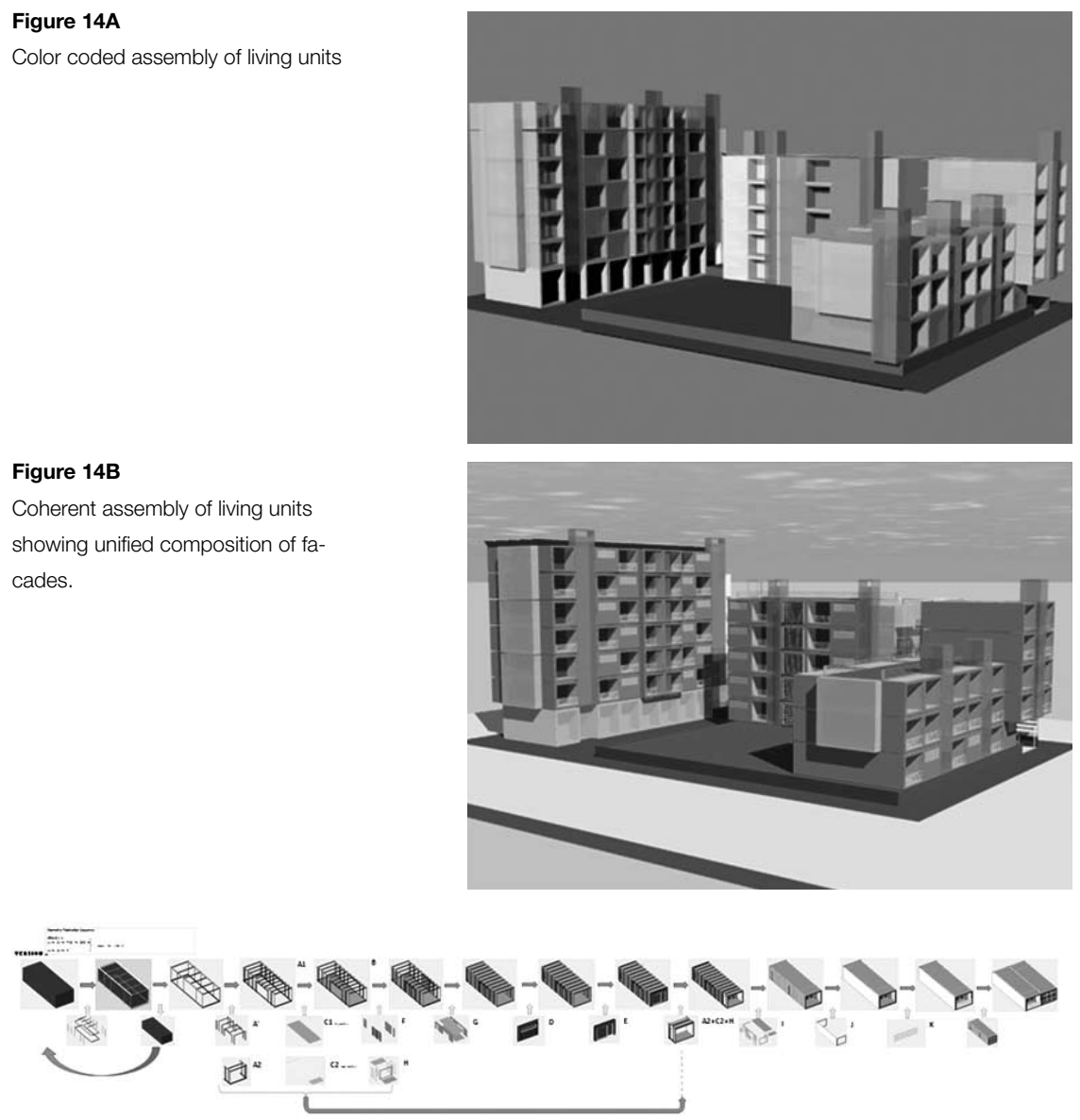

\section{Figure 15}

An assembly line reconstruction using

virtual prototyping

\section{Figure 16}

Module, Subassembly and part hierarchy relationship

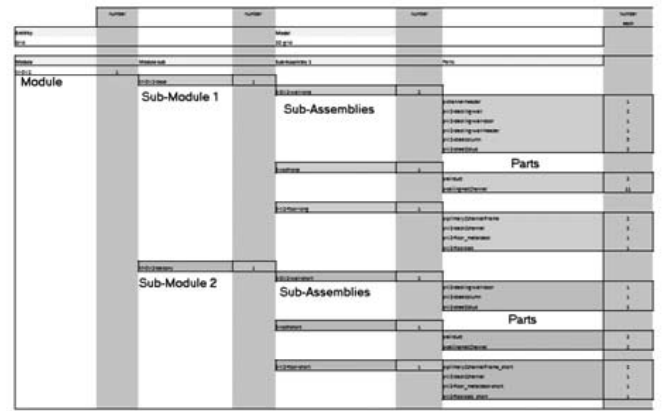

63 - ARCC Journal / Volume 5 Issue 2 - 63 

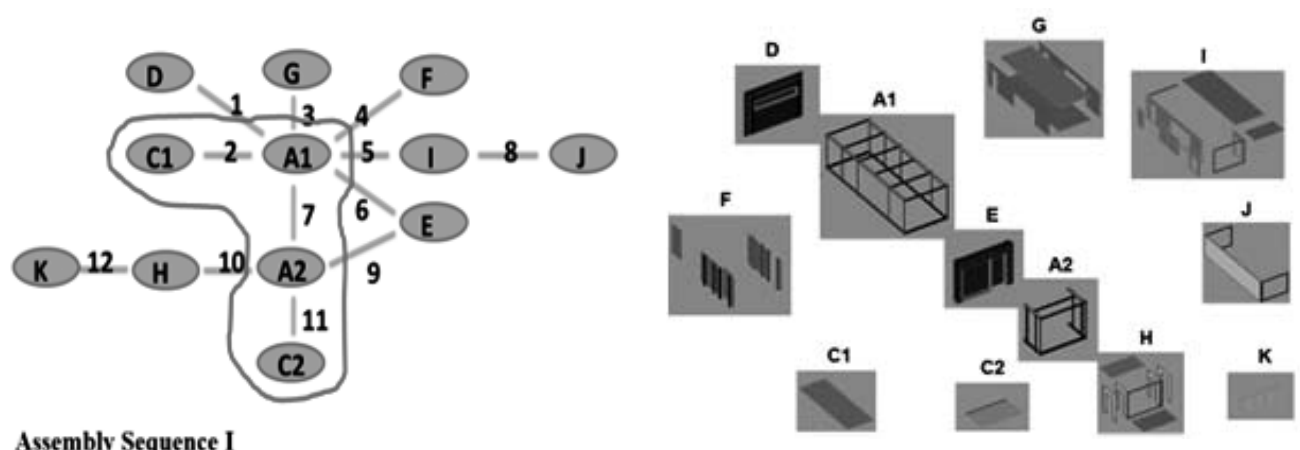

\section{Assembly Sequence I}

$7->(2,11)->1->(6,9)->4->3 \rightarrow 10->5->8->12$

\section{Figure 17}

Sequence generation based on

established relationships- 1 st variant
Figure 18

Module Decomposition into subassemblies

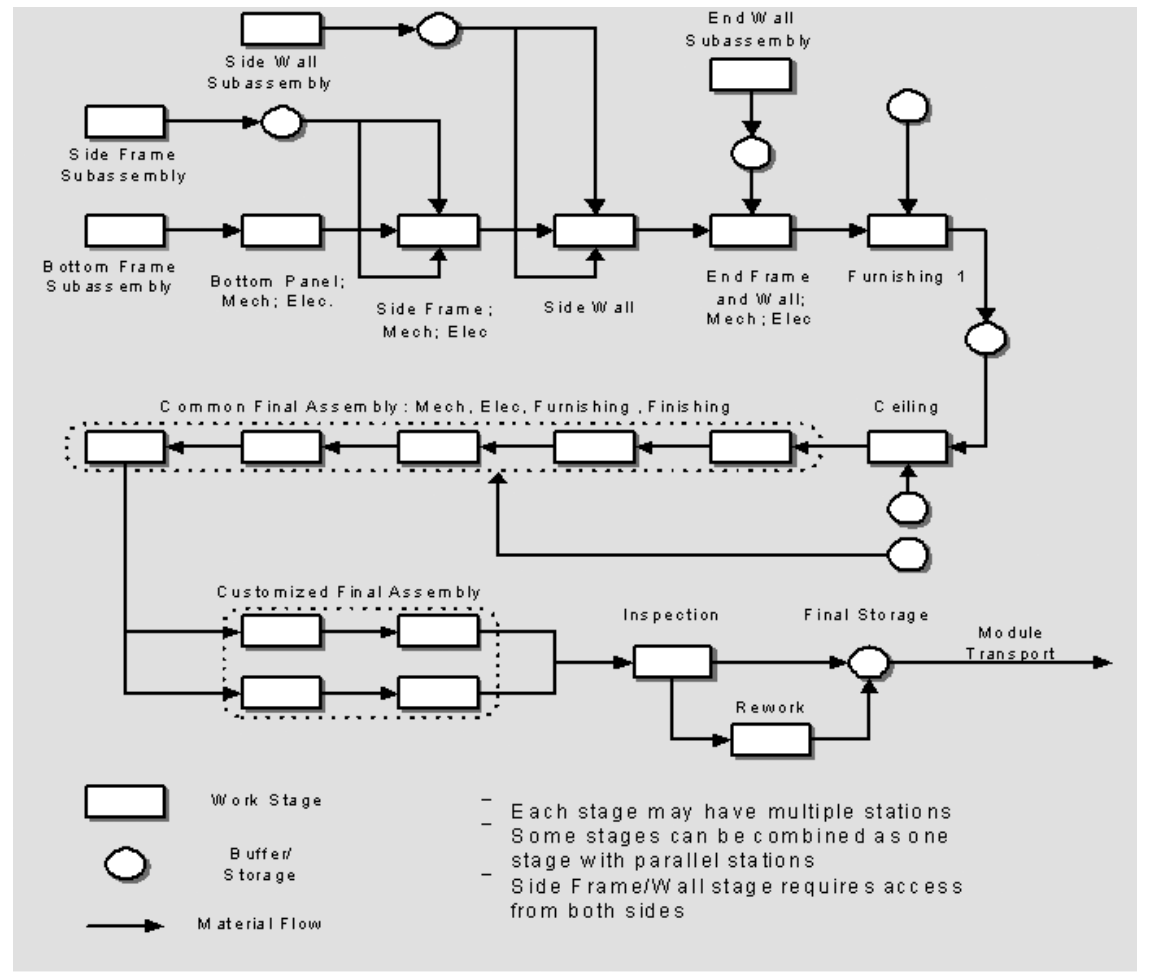

Figure 19

A model for a customized modular housing production line 
portation throughout the whole process. Because of the strong interrelationships between design, manufacturing and supply for prefabricated housing, the manufacturing process is being optimized in terms of the total cost and time spanning from the component supply to the final housingmodule delivery.

We are pursuing concurrent design of subassemblies and assembly systems within a vertically integrated supply chain. The related decisions include component modularization, subassembly identification, assembly system configurations, and supply chain configurations. The technical constrains include available module fabrication capability, transportation, and construction site environment. The given conditions are construction time span, module variety, module demand, and assembly precedence relations. Mass customization concepts are in the process of being applied to subassembly identification and supply chain configuration to provide a variety of customized housing-modules.

An indicative system decomposition is shown in figure 18 which demonstrates the basis by which to establish a series of sequence generation scenarios as shown in Figure 17. Relationships are established from the module decomposition and are then recomposed in the most efficient manner that accounts for delayed differentiation (or customized manufacturing).

In conjunction with various proposed assembly-supply chain configurations and subassembly decomposition, a proper assembly system will finally be designed and constructed in collaboration with our manufacturing partnerships.

Traditionally, a fixed location layout or configuration has been used for building houses on site and in the factory. However, concepts of moving assembly lines and lean

manufacturing can be applied to design the housing-module assembly system, similar to automotive and aircraft manufacture. Moving assembly lines can be very efficient in terms of productivity and a model for production is shown in Figure 19.

\section{Conclusions}

1. A suitable development model for future affordable housing design has been developed.

2. A detailed analysis of demographics has resulted in a variety of unit housing typology configurations, each of which can be customized.

3. This research is set to create new opportunities for affordable housing through the application of digital and automotive technologies.

4. A new prefabricated building product that can be customized has been achieved through virtual modeling that incorporates flexible living arrangements both for an entire building project as well as for more detailed layouts within the living units that allow for modifications over time.

5. Modular prefabricated construction, based on industrial design and contemporary manufacturing principles, will enable an affordable and better-quality product that takes advantage of the economies of mass and customized production procedures.

6. Key manufacturing procedures using virtual prototype modeling have formed the basis of alternative production scenarios that include supply chain management, production line design and facilitating the creation of mass customized products.

65 - ARCC Journal / Volume 5 Issue 2 - 65 